\title{
Universiteit
}

Leiden

The Netherlands

\section{Freely disposable time: a time and money integrated measure of poverty and freedom}

Hobbes, M.; Groot, W.T. de; Voet, E. van der; Sarkhel, S.

\section{Citation}

Hobbes, M., Groot, W. T. de, Voet, E. van der, \& Sarkhel, S. (2011). Freely disposable time: a time and money integrated measure of poverty and freedom. World Development, 39(12), 2055-2068. doi:10.1016/j.worlddev.2011.04.005

Version: $\quad$ Publisher's Version

License: $\quad$ Licensed under Article 25fa Copyright Act/Law (Amendment Taverne)

Downloaded from: https://hdl.handle.net/1887/3193888

Note: To cite this publication please use the final published version (if applicable). 


\title{
Freely Disposable Time: A Time and Money Integrated Measure of Poverty and Freedom
}

\author{
MARIEKE HOBBES \\ Leiden University, The Netherlands \\ WOUTER T. DE GROOT \\ Leiden University, The Netherlands \\ Radboud University, Nijmegen, The Netherlands \\ ESTER VAN DER VOET \\ Leiden University, The Netherlands \\ and \\ SUKANYA SARKHEL * \\ St. Xavier's College, Calcutta, India
}

\begin{abstract}
Summary. - This paper develops, tests, and discusses a metric for livelihood assessment that integrates cash flow and time use households. It expresses how much time the household adults have left after satisfying the household's basic needs (e.g., for food, sleep, care, consumables, and leisure). This "freely disposable time" (FDT) may be put to any use available and allowed in the local context, such as above-basic leisure, work to acquire above-basic consumer goods, or investments in the future such as education or soil conservation. Thus, $F D T$ represents people's freedoms and a key condition for any out-of-poverty strategy. The FDT methodology is illustrated with a number of characteristic livelihood strategies and tested on peri-urban farming livelihoods in India and some typical Dutch households. The FDT outcomes, methodology, strengths, and limitations are compared with those of an allied, "Discretionary Time" indicator, paired time/money indicators and purely monetary (e.g., income or expenditure) indicators of poverty and welfare.

(c) 2011 Elsevier Ltd. All rights reserved.
\end{abstract}

Key words - livelihoods approach, poverty assessment, social indicator, basic needs, time poverty, poverty line, freedoms, discretionary time, India

\section{INTRODUCTION}

Creating sustainable livelihoods to eliminate poverty is today's adage in rural development (Ellis, 2000; Hussein, 2002). As a format to capture the notoriously complex intricacies of rural livelihoods, the Sustainable Livelihoods approach has evolved from the late 1980s onward, based on Sen's (1981) entitlements and the work of Chambers and Conway (1992), Scoones (1998) and Ellis (2000). Various livelihoods assessment frameworks are now in use, for example, by the FAO, DFID, the World Bank, CARE, and UNDP. Designed primarily as a guide toward qualitative understanding (Scoones, 1998), results of these frameworks cannot be benchmarked against quantitative standards such as poverty lines and cannot be used for comparisons or to trace development over time. This paper aims to enrich the livelihoods approach with a quantitative indicator that integrates fundamental aspects of any livelihood. This, in our view, implies that the indicator should integrate money and time. In integrated time/money metric can express fundamental livelihood aspects that separate time or money indicators such as income or expenditure fail to capture. One example is that low-income households that still avail of time that could be spent to generate more income should be assessed as fundamentally better off than households that have the same income but need all their avail- able time to provide that income. As we will see in Section 2 , no metric is available yet that can do this on the level of individual households or household members.

The present paper, therefore, proposes a methodology that integrates all livelihood dimensions that are expressed primarily in monetary terms (e.g., cost of food, healthcare, consumer goods, or school) with those that are expressed primarily in time terms, for example, sleep, care, leisure, work, or community participation. Its synthetic result is named Freely Disposable Time (FDT). The basic intuition of FDT is that it is the time that people have left after the satisfaction of basic needs, and therewith represents the time that people can use to gain additional income, or to invest in the future, or to leisure, or any other choice available in the local context. $F D T$ is the time not dictated by the necessities of life. Defined formally, Freely Disposable Time is the time that a household's productive adults, averaged between them, have left after fulfilling the basic needs

\footnotetext{
* The data were gathered in the framework of the project "Treatment of water for irrigation and potable use (TIPOT)," co-funded by the European Union. We thank the people of Kashimpur for their kindness and patience. We thank the Ramakrishna Vivekananda Mission, Calcutta, for its support, and two anonymous reviewers for their insightful and pervasive comments. Final revision accepted: March 1, 2011.
} 
that they need to supply for themselves and their dependents. Basic needs here relate to the full range of necessities of a decent life, for example, physiological needs, food, shelter and care needs, social obligations, basic consumer goods, and so on. The FDT definition implies that in the present paper, we do not differentiate between the productive adult household members; see Section 3 for more details.

Note that FDT is not leisure or spare (non-working) time. FDT may be put to many types of use, and leisure is only one of those. In fact, most people prefer to work part of their freely disposable hours, for example, in order to acquire luxury goods or send a child to college. Many people in Western societies have much FDT but feel time-pressured nevertheless; see Goodin, Rice, Parpo, and Eriksson (2008) on the "time pressure illusion" and Gershuny (2005) on being busy as a status symbol.

As will be exemplified in Section 4, the FDT metric is sensitive to many more relevant changes in household livelihoods than separate time or money indicators are. Birth of a child reduces FDT because of its care needs. Decreasing food prices improve FDT because less hours of work are needed to fulfill the basic food need. The arrival of a solar cooker improves $F D T$ because less time is needed to search for firewood. Higher wages improve $F D T$. Old age reduces $F D T$ because more time is needed for basic chores and self-care. Maybe just as importantly, Section 4 also shows that FDT is insensitive where it should. For instance if people decide to forego of immediate income and/or expenditure in order to invest time and/or money in vocational training or building terraces on the farm, $F D T$ does not change, because these are only choices within people's available FDT. They are choices of what people decide to do with their time and money. It does not make them poorer, as income or expenditure indicators would suggest.

We have chosen for the time dimension to express the money/time indicator because of time's foundational and universal character. This implies that in the FDT calculation, cash flows are converted into their time equivalents through the income per hour (roughly, the wage rate) of the household. This method also enhances the comparability of FDT worldwide, since PPP conversion is included in the wage rate.

$F D T$ is conceptually equivalent to Goodin et al.'s (2008, p. 34) concept of "Discretionary Time" but differs in methodology, as will be shown later. Like Discretionary Time, the FDT concept is applicable to the rich and the poor alike, and may, therefore, be used as a universal poverty or wealth indicator. The fundamental poverty line is when $F D T=0$, meaning that people need all they can do, that is, all the time they have and all the cash they can generate with it, to satisfy their basic needs. At this level, people are trapped in poverty, with neither time nor cash left to invest in the future. 1 On the other side of the spectrum, very high income implies that the acquisition of basic needs requires only very little time in income generation. Yet, since everybody's day has only $24 \mathrm{~h}$ and everybody needs some 10 of those for basic sleep, self-care and leisure, all very high incomes will congregate at around $13-14 \mathrm{~h} /$ day of $F D T$. The relatively poor will be found in a much broader range, as Section 5 will show. As Goodin et al. (2008, p. 3) put it, the time metric expresses the decreasing marginal utility of income.

Against this background, the objective of this paper is to document, illustrate, test, and discuss a metric of Freely Disposable Time of households. In our examples, some bias will be toward relatively poor farming households because these provide the technically most difficult nut to crunch, for example, due to subsistence production. The paper is structured as follows. Section 2 gives a brief overview of the history and members of the family of combined time/money indicators. Section 3 then presents the FDT methodology. In Section 4, we look at the FDT outcomes of various choices of a simplified example household, and compare these to what a number of monetary indicators say about the same choices. Section 5 then presents the outcomes of an empirical FDT application on complex, peri-urban livelihoods in India, with some households from the developed world added for comparison. Section 6 provides a broad discussion, comprising a comparison of empirical FDT and Discretionary Time outcomes but focusing in particular on issues of metric validity, that is, the value of FDT for people's incomes, freedoms, and well-being. Along that line we will not only discover strengths of $F D T$ but also two caveats. The paper is rounded off by a summary and a reflection on indicator choice in research.

\section{COMBINED TIME/MONEY METRICS}

Many livelihood indicators exist already. Most of them focus on the monetary side of livelihoods, such as GNP per capita and household income or expenditure measures, sometimes in combination with a cost-of-basic-needs estimate (Ravallion, 1994; Ravallion \& Bidani, 1994; Wodon, 1997). Other indicators focus on the time side of livelihoods, such as time poverty in Bardasi and Wodon (2006). Some indicators are of a more multi-dimensional nature, such as the $\mathrm{Hu}-$ man Development Index and multi-dimensional poverty indicators. These lack true integration, however, because they aggregate their components in an arbitrary manner, for example, just adding up the various "life satisfactions" (Rojas, 2008). The FDT metric on the other hand belongs to recently sprouted family of poverty/welfare indicators that combine time and cash flows. This section supplies an overview.

\section{(a) Origins: Becker (1965) and Vickery (1977)}

Becker (1965) proposed that a household's resources could be measured by its "full income," defined as what it could earn by devoting all its time to income-generation activities and activities directly necessary to sustain these activities, such as a minimum of sleep. Becker's method has been criticized for failing to take into account that paid work to fill all these hours may be locally unavailable (Folbre, 2004). Vickery (1977) followed subtler course, calculating a combined money/time poverty spectrum. People with little spare time have a higher income poverty line than people who have more time available to compensate low income by searching for bargains, cook food from fresh ingredients, etc.; see Douthitt (2000) for an update.

\section{(b) Land-time budget analysis}

From within the rural development and farming systems tradition, Giampietro (2004) developed "land-time budget analysis" to assess the performance of the time and land budgets that people have available. Starting point of the analysis is the total number of hours per year available in the studied group (society, village, and household). Various categories resembling basic needs are then subtracted, such as the time needed for sleep, leisure, education and chores, the total time of the non-productive household members, and the time needed to farm for auto-consumption, pay taxes, and buy agricultural inputs. The time left can be used to produce cash, either on or off farm. How much "net disposable cash" this can be depends on a parallel system for the availability of land. 
Land-time budget analysis does not offer a coherent system of data categories and calculation rules, which hampers application in empirical cases (Gomiero \& Giampietro, 2001; Grünbühel \& Schandl, 2005; Hobbes, 2005; Pastore, Giampietro, \& Ji, 1999). For instance, food needs are either not (Giampietro, 2004, p. 396) or fully (Pastore et al., 1999) subtracted from net disposable cash. Yet, Giampietro's principles have been a major source of inspiration for developing FDT.

\section{(c) Paired money/time indicators}

Vickery's (1977) idea has recently been carried forward in the form of paired money/time indicators, exemplified by Bardasi and Wodon (2009) on Guinea and Burchardt (2008) on the United Kingdom. Bardasi and Wodon (2009) focus their analysis on people who are time as well as consumption poor, that is, those who work long hours out of necessity to make basic ends meet. The relevance of this approach is shown by that the head count of this category is only about half of those who are only time-poor. Burchardt (2008) defines "free time" as $24 \mathrm{~h} /$ day minus time spent on sleep, personal care, paid work, and unpaid work. The analysis of households then takes place on the two-dimensional plane defined by the axes of disposable income and free time, that is, distinguishing between people with low pay and few obligations of unpaid work, people with low pay but many obligations, and so on.

\section{(d) Integrated time/money indicators: DT and FDT}

All methods described above use a wage rate to convert money and time. Burchardt (2008), for instance, applies the income per hour to set the slope of the various income/free time combinations that households have available. Bardasi and Wodon (2009) apply the income per hour to assess if households would hit the income poverty line if they would work a decent number of hours. Both paired indicator approaches refrain, however, from using the income per hour to calculate a single, integrated metric. This does have advantages. The paired indicators maintain more detail on time and money separately, enabling for instance to distinguish between income-poverty caused by low wages and income-poverty caused by working only few hours. On the other hand, a two-dimensional indicator is more cumbersome in comparative work. It is noteworthy in this context that both Burchardt (2008) and Bardasi and Wodon (2009) discuss single-country cases, contrary to the cross-country comparisons in Goodin et al. (2008) and the present paper.

As said in Section 1, Goodin et al.'s (2008) "discretionary time" $(D T)$ and our "freely disposable time" (FDT) are conceptually equivalent. They were developed independently from each other, originating from time and welfare studies (e.g., Campbell, Converse, \& Rogers, 1976, p. 349) and from rural development studies, respectively. As a result, many differences between DT and FDT show up on the lower, methodological level. First of all, $D T$ has been constructed for industrialized countries and FDT for the developing ones and with that, the $D T$ assessment method gives more attention to tax and welfare regimes, less attention to multiple livelihoods including subsistence, and less attention to non-child dependents (e.g., elderly or HIV/AIDS patients). Second, $D T$ was developed as a system to interpret national statistics while the FDT framework was constructed through and for field-level work, paying more attention to mastering livelihood complexities and less to handling dataset complexities. Third, contrary to the $D T$ methodology, the FDT framework keeps temporary or chronic deficiencies on separate categories (food, sleep, care, goods, etc.) explicit until the very last moment before everything is collapsed into the single FDT indicator. Fourth, the DT and DFT methodologies differ in their approach to basic needs. In the $D T$ system, they are largely relative, for example, setting the income poverty line as $50 \%$ of the median income in a country. In the FDT system, basic needs are largely absolute, for example, the FAO calories standard. This requires more empirical work but makes FDT independent from national statistics and more open to explore scenarios such as the impact of changing prices, the addition of a child or sick to a household or the acquisition of a solar heater that frees female time from firewood gathering. These differences between $D T$ and $F D T$ seem substantial enough to justify a separate reporting of FDT here and a separate term for the time being.

\section{THE $\boldsymbol{F D T}$ ASSESSMENT METHOD}

This section describes the basics of the FDT methodology. $F D T$ assessment uses data on how people spend their time and money on various categories. Money expenditures are converted to time expenditures using the household's income per hour. For instance, if five hours of work deliver $100 \$$, spending $100 \$$ is the equivalent of spending five hours of work. The operational framework of $F D T$ assessment is taken up in the Appendix. It can handle different basic needs per household member, subsistence production, temporary or chronic deficits in basic needs, and all income elements such as wages, farm profits, remittances and "time gifts" such as help from neighbors.

The composition of a household is important for FDT assessment. A young child or sick person, for instance, adds to the household's basic needs but its freely disposable time does not make a relevant difference for the household. Therefore, the FDT assessment focuses on the productive adults (PAs), with the other members of the household present in the analysis in the form of adding to the basic needs that these PAs have to provide. Non-PA members may sometimes help out, for example, doing chores; this is added as gifts or aid to the PAs' account. The framework's major limitation is that it takes the household level as its unit of analysis and calculates the average $F D T$ per PA, without intra-household differentiation, for example, between men and women, or parents and adult children. This is a practical choice for the present paper, not a necessity. Time use data usually describe behaviors of each household member and with some effort, also data on wages and expenditures may be differentiated. Basic needs present more difficulties because the distribution of householdlevel needs (obligations) is a normative matter (see, e.g., Goodin et al., 2008 on "household regimes") but essentially, nothing stands in the way of individual-level FDT assessment.

Since this paper focuses on the principles of $F D T$ assessment rather than exact outcomes, issues of quantification of basic needs are not a major concern here. We will quantify basic needs grounded in common sense, field data and relevant literature, but without lengthy justifications. The Appendix shows how based on household-level time use, cash flow and basic needs data, a time for the basic need and a time deficit or (more often) a time surplus are generated for each category that a household spends time and/or cash on, for example, food, sleep, care, agricultural inputs, knowledge acquisition, savings, travel, on-farm, or paid work. The basic formula is that the time equivalent of any activity is calculated as the time spent on it plus the cash spent on it divided by the income per hour. 
Keeping the time deficits and surpluses separate helps identify chronic problems of households. It also gives insight into how households may use temporary deficits to create more working time in periods of harvest, exams, disaster, or sickness. Basic needs would not be basic needs if deficits could continue for a long time, however. In the longer run and in a principled outlook, therefore, $F D T$ is the aggregate of all surpluses minus all deficits.

The Appendix includes a shortcut method of FDT assessment that jumps over the separate calculations of deficits and surpluses but requires less data. Based on the household composition, the basic needs list and the local wage rate, a time requirement for basic needs is calculated, and FDT is assessed as $24 \mathrm{~h} /$ day minus that requirement. This method comes close to Goodin et al.'s (2008) DT methodology. The next sections follow the full FDT method.

\section{FDT OUTCOMES IN A SIMPLIFIED EXAMPLE}

This section gives a simplified numerical example to illustrate the principles and properties of $F D T$, and to compare its outcomes on poverty with those of some monetary indicators. A general discussion on the differences between indicators is supplied in Section 6.

\section{(a) Illustrating FDT on a sequence of household strategies}

Table 1 shows the FDT assessment of a hypothetical singleactor household living a life of only six categories on which the actor spends time and/or cash. Each overarching column of the table focuses on a different profile ("strategy") of how this actor spends his/her time and income. Within each profile, five columns summarize the FDT assessment. The first column shows the basic needs $(B N)$ on all categories. The second and third columns depict the time $(E X h)$ and money $(E X \$)$ expenditures of the actor on these categories. The $T_{B N}$ column reflects the time/cash integrated time equivalents needed to satisfy the basic needs. $T_{S U R}$ is the surplus time, that is, the time left after the basic needs have been fulfilled. Because the actor has no time deficits, the total of the time surpluses equals $F D T$ for each profile.

The category of sleep, self-care and leisure has a basic need of $10 \mathrm{~h} /$ day. In the initial profile (first overarching column), the actor spends $14 \mathrm{~h}$ /day on this category, meaning that this category contains $4 \mathrm{~h}$ /day of surplus time. The basic need to keep the household in order without any household appliances is $2 \mathrm{~h}$ /day and the actor's time expenditure is indeed $2 \mathrm{~h} /$ day. Consequently, this category contains no surplus. There is no basic need for labor. Labor time is always canceled out, irrespective of wage and hours worked, by the cash received for it ( $E X \$$ with the minus sign). In the example, working $8 \mathrm{~h}$ per day at a wage rate of $1 \$ / \mathrm{h}$ results in $(8 \mathrm{~h} /$ day $)-(8 \$ /$ day) $/(1 \$ / \mathrm{h})=0 \mathrm{~h} /$ day of surplus time. The cash earned is spent on other categories, for example, to buy food, and may make $F D T$ visible there. In the first profile, the actor spends $5 \$$ /day on food which, at the given wage of $1 \$ / \mathrm{h}$, is equivalent to $5 \mathrm{~h}$ of work. The basic need of the food category has been set at $4 \$$ day. Thus, out of the $5 \mathrm{~h}$ time/cash integrated time, $4 \mathrm{~h} /$ day is needed to satisfy the basic need $\left(T_{B N}\right)$ and $1 \mathrm{~h} /$ day is surplus time $\left(T_{S U R}\right)$, which could be spent on other categories. Further, we see that the actor spends his/her remaining $3 \$$ day on other goods, which is equivalent to $3 \mathrm{~h} /$ day of time/cash integrated time. Assuming a basic need of other goods of 2 \$/day (for lighting, heating, clothes, etc.), $1 \mathrm{~h}$ /day is FDT. All cash now being spent, noth-

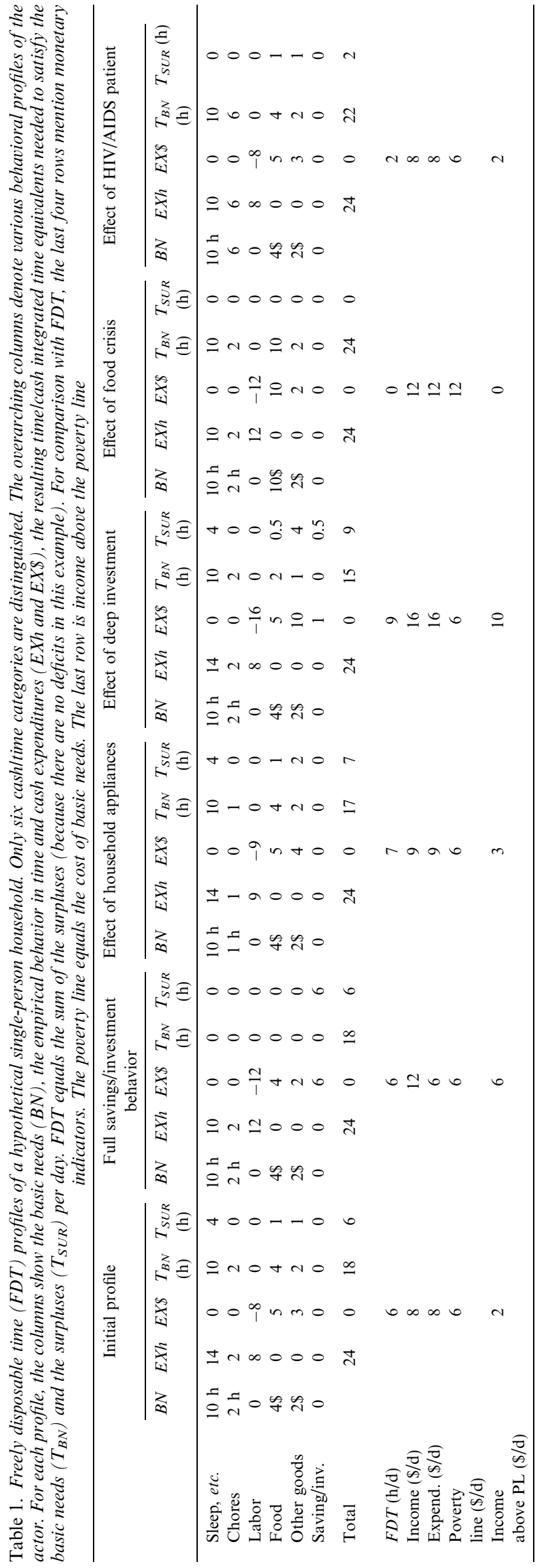


ing goes to the savings category. Adding up all time surpluses, $F D T$ is $6 \mathrm{~h}$ /day. What the actor apparently does in this profile is to spend much of this freedom (4 out of the $6 \mathrm{~h}$ ) on leisure.

What could this actor do alternatively with this FDT? By way of example, the next profile in Table 1 shows the effect of a rigorous savings/investment strategy in which the actor has given up all above-basic sleep, leisure, food, and consumables and puts all FDT to work for the savings/investment category. Assuming a sufficient local labor demand to maintain the wage rate of $1 \$ / \mathrm{h}$, the actor now works for $12 \mathrm{~h} /$ day (24 minus the basic needs for sleep, self-care, leisure, and chores), bringing in $12 \$$ day. This is the "full income" as defined by Becker (1965). Out of the 12 \$/day, 4 \$/day is again needed for the basic needs of food and $2 \$ /$ day for other goods. The remaining $6 \$ /$ day, equivalent to $(6 \$ /$ day $) /(1 \$ / \mathrm{h})=6 \mathrm{~h} /$ day of $F D T$, is in the savings category. Note that all the while, the FDT total has stayed the same $6 \mathrm{~h} /$ day. The FDT metric is insensitive here. The actor is not assessed as better off (higher $F D T$ ) when working more hours. Neither is the actor assessed as poorer when foregoing luxuries in order to save or invest. The actor does get a higher FDT, however, when wages rise compared to basic need prices, or when investments begin to pay off, as the next profiles show.

The third profile in Table 1 depicts the situation after the actor has decided to buy time-saving household appliances from the savings. The basic need of the chores has now dropped to $1 \mathrm{~h} /$ day. Consequently, FDT rises to $7 \mathrm{~h}$ /day. If the actor then decides to go back to the original levels of sleep, self-care, leisure, and food, he/she can work one hour more and spend the extra 1 \$/day on any other purpose, for example, consumer goods as in the example.

Alternatively, the actor may decide to invest the savings in some "deep," out-of-poverty strategy, for example, through vocational training or, if he/she is a farmer, hiring labor for building terraces for a higher yield or a new crop. In the fourth profile, we assume that as a result of this investment, the actor's wage rate has risen to $2 \$ / \mathrm{h}$. Bringing the sleep, self-care, leisure, chores, and labor time back to the initial levels, the actor now earns $16 \$ /$ day, out of which he/she spends 1 extra $\$ /$ day on food, which now costs only $0.5 \mathrm{~h} /$ day of $F D T$ due to the doubled wage. Of the remaining $11 \$ /$ day, the actor spends 10 on other goods, leaving $1 \$ /$ day $(0.5 \mathrm{~h} /$ day $)$ for savings. FDT stands at $9 \mathrm{~h}$ /day.

Real poverty, as said, is when $F D T=0$. In Table 1 this has been simulated by a food crisis that puts the price for the basic food basket at $10 \$ /$ day. The only option left for the actor now is to work maximum hours, 12 per day in this case, for bare survival, spending all time and generated income on basic needs.

The final profile in Table 1 simulates the effect of the addition of an HIV/AIDS patient to the household. The assumption is that the patient requires some $4 \mathrm{~h}$ per day of care ("chores" in the table) but that the monetary expenditures for the patient (food and medicines) are borne by non-household family members. The effect of this is that compared to the initial profile, the actor's $F D T$ drops from 6 to 2 h per day.

\section{(b) FDT outcomes compared to monetary poverty indicators}

The two lines below FDT in Table 1 show the incomes and expenditures (on food and other goods) of each profile. This allows a comparison of $F D T$, income and expenditure as poverty indicators.

In the second profile, the actor following an investment strategy is assessed as better off than before he decided to do so according to the income indicator. According to the expen- diture indicator on the other hand, the actor is assessed as poorer than before ( $c f$. Van Campenhout, 2006, p. 410). Standing above this contradiction, the only change in FDT terms is that the actor now spends the same $F D T$ of $6 \mathrm{~h}$ /day in a different manner; he/she has not become better or worse off.

In the next two profiles, incomes and expenditures rise as does FDT. Note, however, this if the actor would have decided to spend the extra FDT on non-monetary elements of wellbeing (leisure, building social capital, etc.) rather than on extra work and consumption, this would have gone unnoticed in the monetary indicators.

In the food crisis profile, the actor works all possible hours for bare survival without any other option left $(F D T=0)$. Yet with income and expenditure now at 12 \$/day compared to the initial $8 \$ /$ day, the actor is assessed as better off than before by both the income and expenditure indicators.

The final profile (HIV/AIDS) shows no change in the monetary indicators in spite of that the actor now has to spend the majority of his/her spare time on care, having lost $4 \mathrm{~h}$ of FDT per day.

One anomaly of the monetary indicators is redressed if basic needs are included in the picture, for example, subtracting the cost of basic needs from the actual income. The cost of basic needs in the first four and the last profiles and is $4+2=$ $6 \$$ /day. In the food crisis profile it is $10+2=12 \$ /$ day. The bottom line of Table 1 gives the incomes above this cost-of-basic-needs $(\mathrm{CBN})$ poverty line. In the food crisis profile, the income above CBN stands at zero, in accordance with FDT. Note, however, that this congruence is present only if the rise of basic needs is indeed a rise in monetary needs. In the final profile, the actor is confronted with a crisis in time terms, in this case the care for an HIV/AIDS patient. The same effect presents itself when the actor is disentitled to gather firewood in a nearby forest, for instance, or when climate change would result in much more intensive house maintenance needs. Monetary indicators miss this mark, contrary to FDT. On the other hand, pure time indicators would miss many (monetary) others.

We may conclude here that only an integrated metric such as $F D T$ picks all relevant changes up, while being insensitive to changes that merely result from different choices within a same welfare level.

\section{EMPIRICAL TEST OF THE $\boldsymbol{F D T}$ METHODOLOGY}

Hypothetical households may serve to illustrate many of FDT's characteristics, as shown in the preceding section. We also confronted the methodology with real-world cases in order to develop it fully and test its robustness in practice. Farming households in the village of Kashimpur, at some $40 \mathrm{~km}$ north-east of Calcutta, India, were selected for the field test. The main reason for this choice was the complexity of livelihoods. The households in Kashimpur grow many different crops in three different seasons. Some land is owned, other land is share-cropped. Some of the harvest is used for subsistence, another part is sold. Most households have some cattle that they feed from all kinds of sources and use to supply milk for the family but also to sell. Several farmers are also part-time milk middlemen. Other household members are factory workers or part-time sewers, shopkeepers, students, teachers, or singers. Others have a petty trade such as selling biscuits at the markets. Some households gather firewood for cooking; others buy firewood, or gas, coal, or dung cakes. Some households hire labor for house cleaning or agriculture; others hire draft animals for plowing. 
Some have their own wells for irrigation; others pay (sometimes) to receive water from private or village wells. Local measurements contain "maunds," "paunds," "bighas," "bunches," "bags," and many others. If the FDT methodology could handle this, we thought, it could handle anything.

Thirty-three households were randomly selected from a list of all households engaged in farming. One dropped out during the field work, resulting in a sample of 32 households, comprising 116 productive adults ${ }^{2}$ and 27 dependents. Productive adults were interviewed, with elderly supplying additional details. Data were gathered during 2005-06, focusing on the livelihood components, with overall time use (3-day recall) and cash flows added. Interviews for the time study were held in a 10-day rhythm, while the others were scattered over time. Data were entered in an Access database structured through the FDT framework (Appendix).

Two households were added from the industrialized world. One is the first authors' own in the Netherlands, chosen because of perfect data availability. This is a household with three young children, a somewhat higher than median income and no special features in expenditure pattern. Two situations were analyzed, one with au pair help and one without, in order to show the effect of this choice on FDT. The second household is only semi-empirical because the data were compiled from informal information. It represents a lone mother in the Netherlands, full-time employed for a minimum wage, receiving some subsidies on house rent, child care, and child support. The Appendix (Table 3) shows the basic needs data that underlie the FDT outcomes.

The methodological experience gained in the empirical study was that the database design had to be adapted several times to accommodate newly found complexities but worked smoothly in the end, generating the empirical FDTs from the primary data with a few mouse clicks and scenarios easily explorable. The empirical results are summarized in Table 2, showing the time/cash integrated time needed to satisfy basic needs $\left(T_{B N}\right)$, time/cash integrated time surpluses $\left(T_{S U R}\right)$ and deficits $\left(T_{\mathrm{DEF}}\right)$ for five Kashimpur households and the three Western cases.

We will first look at some of the categories (rows). The "food" row shows that most productive adults (PAs) in Kashimpur spend some $2-3 \mathrm{~h}$ /day on its provision, depending on their households' composition, the efficiency of their subsistence agriculture and their income per working hour. The richest household in Kashimpur has a very high income and hence needs only $0.3 \mathrm{~h} /$ day for basic food. Several Kashimpur households display significant food deficits. This is often found in food studies in India (Chandrasekhar \& Ghosh, 2003). The "school" category has basic needs as per Table 3 that depend on the number of children in primary school age as well as the PAs' income per hour. Surpluses express that not only children but also PAs go to school, for example, a 16 years old going to high school. "Savings and investments" expresses the household's cash balance, divided by the income per hour. Purely monetary indicators (net income per capita for all households and expenditures per capita for the Indian households because expenditures are often used as key indicator in developing countries) are taken up in the last two rows for reasons of comparison. One major difference between the FDT and the monetary indicators is that the three poorest households in Kashimpur are way below the 1 \$/day poverty line, but not destitute in FDT terms. With freely disposable time of some 5-8 h/day for each productive household member, they have substantial time left that can be spent on various uses, such as (in Kashimpur), wage labor, cottage industry, leisure, or childcare. Another difference is in the sequence of the second and third households. The second has substantially lower FDT in spite of a somewhat higher income per capita. The household composition plays a major role here.

The first household of Table 2 represents the poorest in Kashimpur, in both monetary and FDT terms. This household creates some $10 \%$ of its time surpluses through a food deficit. It spends its $6 \mathrm{~h}$ of surplus time on above-basic care, self-care, cooking, chores, and religion. The profile of this household is to keep the female PA away from wage work and concentrate on keeping up a well-organized, clean, and proper family, despite very low cash income and expenditure.

The second household of Table 2 represents another way of being poor, and yet not so poor, in Kashimpur. Its higher income and expenditure reflect its stronger market orientation; the male PA is involved in milk sales and van driving. Much of the time surpluses are created by this and is again put to care, self-care, and other non-cash activities, but not fully as in the previous household; $0.6 \mathrm{~h}$ per day is spent on "luxury" goods (non-caloric consumption surplus) and $0.8 \mathrm{~h}$ per day to savings ( $15 \%$ of surplus time).

The third case in the Table represents the first of Kashimpur's middle-level households in FDT terms. As its low income and expenditure illustrate, it has a low involvement in the market, a characteristic shared with the first household. The major difference between those two is that the middle class household is investing, albeit not in savings but in sending one teenage PA to school (see the surplus of $2.3 \mathrm{~h}$ per day in that column).

The fourth household is around the FDT median of Kashimpur. The relatively high income of $1 \$$ per capita per day is mainly derived by marketing farm produce, cottage industry, and trade. The surplus time is spread relatively evenly to support one student, to save, to buy some surplus food and non-caloric goods, to enjoy surplus sleep and leisure, and to give above-basic care.

The next case represents the richest household in Kashimpur. It concerns the traditional landed gentry (zamindar) of the village, in a single person household. This person leads a materially simple life, without spending significant parts of his FDT on surplus food or non-caloric consumption (see also the relatively low expenditures). His surplus time is largely spent on very high levels of leisure, self-care, and community work, a large part of which may be interpreted as maintenance of social capital.

The two Dutch middle-class cases differ only in the presence of an au pair helper. The rise in FDT indicates the overall efficiency of this choice. Per separate category, the major effect of the helper is that some savings are sacrificed (lower surplus) to have more rest, more leisure, and a better organized house (higher surpluses).

The final household in the table represents the poor in the industrialized world: a single mother with three children working full time for a minimum wage. She has a leisure deficit ("time poverty"). Whereas the Indian households hardly spend time on housing, this mother has to work $1.5 \mathrm{~h}$ per day for her basic housing need despite government housing subsidy, due to the much higher cost of housing in the Netherlands. It should be noted here that the children are sent full-time to daycare, so that the mother is able to work. This is only affordable due to government subsidies; the costs that the actor herself has to pay are taken up as basic need in the non-caloric consumption. Still, her FDT is less than those of the poor of Kashimpur. Without the housing and childcare subsidies, her FDT would be negative. 


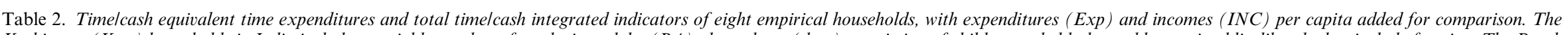

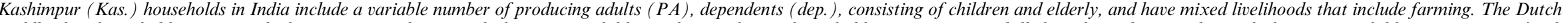

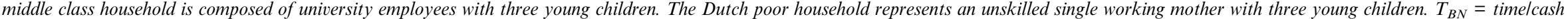

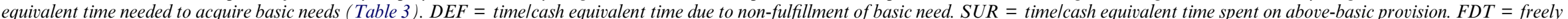
disposable time $=$ total time surpluses minus total deficits. All numbers except the incomes are in hours per day per PA, averaged over the PAs and over the year. The incomes and expenditures are after taxes,

\begin{tabular}{|c|c|c|c|c|c|c|c|c|c|c|c|c|c|c|c|c|c|c|c|c|c|c|c|c|}
\hline & \multicolumn{3}{|c|}{$\begin{array}{c}\text { Kas. poor } 1 \\
(2 \mathrm{PA}, 2 \text { dep. })\end{array}$} & \multicolumn{3}{|c|}{$\begin{array}{c}\text { Kas. poor } 2 \\
(2 \mathrm{PA}, 3 \text { dep.) }\end{array}$} & \multicolumn{3}{|c|}{$\begin{array}{l}\text { Kas. middle } 1 \\
\text { (3 PA) }\end{array}$} & \multicolumn{3}{|c|}{$\begin{array}{l}\text { Kas. middle } 2 \\
\text { (5 PA) }\end{array}$} & \multicolumn{3}{|c|}{ Kas. rich (1 PA) } & \multicolumn{3}{|c|}{$\begin{array}{l}\text { Dutch middle } 1 \\
\text { (2 PA, } 3 \text { dep. })\end{array}$} & \multicolumn{3}{|c|}{$\begin{array}{c}\text { Dutch middle } 2 \\
\text { (2PA, 3dep.,helper) }\end{array}$} & \multicolumn{3}{|c|}{$\begin{array}{c}\text { Dutch poor (1 PA, } \\
3 \text { dep.) }\end{array}$} \\
\hline & $T_{B N}$ & SUR & $\overline{D E F}$ & $T_{B N}$ & SUR & $\overline{D E F}$ & $T_{B N}$ & SUR & $\overline{D E F}$ & $T_{B N}$ & $S U R$ & $\overline{D E F}$ & $T_{B N}$ & SUR & $\overline{D E F}$ & $T_{B N}$ & SUR & $\overline{D E F}$ & $T_{B N}$ & SUR & $\overline{D E F}$ & $T_{B N}$ & $S U R$ & $D E F$ \\
\hline Phys. Inac. & 8.0 & 0.2 & 0 & 8.0 & 0 & 0.1 & 8.0 & 0.6 & 0 & 8.0 & 0.6 & 0 & 8.0 & 0 & 0.4 & 8.0 & 0 & 0.0 & 8.0 & 0.3 & 0 & 8.0 & 0.0 & 0 \\
\hline Leisure & 2.0 & 0.0 & 0 & 2.0 & 0 & 0.3 & 2.0 & 1.4 & 0 & 2.0 & 1.4 & 0 & 2.0 & 3.5 & 0 & 2.0 & 0.3 & 0 & 2.0 & 1.2 & 0 & 2.0 & 0.0 & 0.5 \\
\hline Self-care & 0.6 & 1.9 & 0 & 0.6 & 2.5 & 0 & 0.6 & 2.6 & 0 & 0.6 & 2.7 & 0 & 0.4 & 3.5 & 0 & 0.6 & 0.7 & 0 & 0.6 & 0.7 & 0 & 0.8 & 0.6 & 0 \\
\hline Care & 1.0 & 2.0 & 0 & 1.5 & 1.0 & 0 & 0 & 0 & 0 & 0 & 0 & 0 & 0 & 0 & 0 & 1.4 & 3.6 & 0 & 0.7 & 3.7 & 0 & 3.0 & 1.0 & 0 \\
\hline Chores & 0.8 & 0.5 & 0 & 1.0 & 0.3 & 0 & 0.5 & 0.4 & 0 & 0.4 & 0.4 & 0 & 0.5 & 0.2 & 0 & 1.0 & 0.1 & 0 & 0.3 & 0.4 & 0 & 1.5 & 0.2 & 0 \\
\hline Cooking & 1.0 & 0.7 & 0 & 1.3 & 0.3 & 0 & 0.7 & 0.4 & 0 & 0.5 & 0.3 & 0 & 1.5 & 0.2 & 0 & 0.5 & 0.0 & 0 & 0.3 & 0.1 & 0 & 1.0 & 0.0 & 0 \\
\hline Food & 3.4 & 0 & 0.6 & 2.4 & 0 & 0.3 & 3.0 & 0 & 0.4 & 2.3 & 0.1 & 0 & 0.3 & 0 & 0.0 & 0.2 & 0.6 & 0 & 0.3 & 0.6 & 0 & 0.6 & 0.1 & 0 \\
\hline Non-cal. cons. & 0.5 & 0.0 & 0 & 0.6 & 0.6 & 0 & 0.5 & 0.1 & 0 & 0.3 & 0.4 & 0 & 0.0 & 0.1 & 0 & 0.9 & 0.7 & 0 & 0.8 & 0.7 & 0 & 2.8 & 0.2 & 0 \\
\hline Dur. goods & 0.1 & 0.0 & 0 & 0.1 & 0.1 & 0 & 0.1 & 0.0 & 0 & 0.0 & 0.0 & 0 & 0.0 & 0.0 & 0 & 0.0 & 0.1 & 0 & 0.0 & 0.1 & 0 & 0.1 & 0.1 & 0 \\
\hline Saving/inv. & 0 & 0 & 0.0 & 0 & 0.8 & 0.0 & 0 & 0 & 0.2 & 0 & 2.0 & 0 & 0 & 0.4 & 0 & 0 & 0.7 & 0 & 0 & 0.5 & 0 & 0 & 0 & 0.0 \\
\hline School & 0.1 & 0.0 & 0 & 0.1 & 0.0 & 0 & 0 & 2.3 & 0 & 0 & 1.0 & 0 & 0 & 0 & 0 & 0 & 0 & 0 & 0 & 0 & 0 & 0 & 0 & 0 \\
\hline Housing & 0.1 & 0.0 & 0 & 0.1 & 0.1 & 0 & 0.1 & 0.1 & 0 & 0.0 & 0.0 & 0 & 0.0 & 0.0 & 0 & 0.3 & 0.9 & 0 & 0.3 & 0.9 & 0 & 1.5 & 0.0 & 0 \\
\hline Others & 1.2 & 0.5 & 0 & 1.0 & 0.5 & 0.0 & 0.7 & 0.5 & 0 & 0.4 & 0.5 & 0 & 0.6 & 3.2 & 0 & 0.2 & 1.1 & 0 & 0.2 & 1.3 & 0 & 0.3 & 0.6 & 0.0 \\
\hline Total & 18.6 & 6.0 & 0.6 & 18.5 & 6.2 & 0.7 & 16.3 & 8.3 & 0.6 & 14.6 & 9.4 & 0.0 & 13.3 & 11.2 & 0.4 & 15.2 & 8.8 & 0.0 & 13.5 & 10.5 & 0.0 & 21.7 & 2.8 & 0.5 \\
\hline$F D T$ & & 5.4 & & & 5.5 & & & 7.7 & & & 9.4 & & & 10.8 & & & 8.8 & & & 10.5 & & & 2.3 & \\
\hline $\operatorname{Exp} /$ cap $(\$ / \mathrm{d})$ & & 0.25 & & & 0.39 & & & 0.40 & & & 0.62 & & & 3.70 & & & & & & & & & & \\
\hline$I N C / \operatorname{cap}(\$ / \mathrm{d})$ & & 0.25 & & & 0.48 & & & 0.37 & & & 1.06 & & & 7.25 & & & 46.0 & & & 38.3 & & & 14.7 & \\
\hline
\end{tabular}




\section{DISCUSSION}

This section starts out with brief discussion on stocks of flows as measures of freedoms and poverty. Subsequently we compare some outcomes of FDT and Discretionary Time (DT) studies (Goodin et al., 2008). Next, we explore the problem that people may not be efficient $F D T$ (or $D T$ or income) maximizers, and thus may have a higher potential FDT than their actual $F D T$. We then move to a three-tiered discussion of how to interpret FDT findings: what is the income value, the freedoms value and the well-being value of $F D T$ for households? Finally, we present an overall reflection on $F D T / D T$ versus monetary indicators.

\section{(a) Stock versus flow measures}

Monetary or food intake indicators represent concepts of flows (calories per day, dollars per year, etc.) rather than stock (assets, capabilities, capacities, capitals, and resources). FDT and $D T$ also belong to the flow-based category. The livelihoods approach rejects flow measures, arguing that these merely represent points in time and are not fundamental (Carter \& Barret, 2006). This argument does not seem pervasive. Flows can serve as asset indicator, if sufficiently averaged over time and space (Reardon \& Vosti, 1995, p. 1497) and they can be extrapolated to reveal asset dynamics. Households may be poor in assets but getting richer, for instance. Moreover, poor households survive primarily on flows. Their assets are usually insufficient to bridge significant time spans, which is why they often rely on "maximin" strategies. Besides, as described by Reardon, Crawford, and Kelly (1994) for Africa and Romero (2006, p. 192) for the Philippines, farmers often even invest from flows, for example, constructing terraces little by little as incomes allow.

On the philosophical plane, the "flows/stocks" issue relates to the Basic Needs versus Capabilities debate, since basic needs are made operational by flow parameters such as income, expenditure, food, or hours per day. Capability theorists such as Sen (1987) and Alkire (2002) criticized the basic needs approach (e.g., Stewart, 1985; Streeten, 1979; Streeten, Burki, ul Haq, Hicks, \& Stewart., 1981) for being commodity-focused, insensitive to the importance of freedom, too relativistic to be made operational, and so on. As analyzed by Reader (2006), however, the basic needs approach is not inferior to capabilities theory on any of these accounts.

\section{(b) Comparing FDT and DT outcomes}

As said, FDT and DT assessment methods differ much but the two metrics are conceptually equivalent. In other words, "dong $D T$ " or "doing FDT" at the same place should yield roughly equal outcomes. We focus on that comparison here. Since $D T$ applications have up till now only focused on Western societies, we confine the comparison to the three Dutch $F D T$ examples. In a general sense, the substantial FDT difference of $1.7 \mathrm{~h} /$ day created by the au pair helper in the middle class household (Table 2) resonates with the great attention given to welfare regimes (including childcare regimes) in Goodin et al. (2008) as well as Burchardt (2008) who focuses on the United Kingdom. Possibilities for specific $D T / F D T$ comparisons are limited because Goodin et al.'s DT outcomes represent group averages as opposed to our three specific FDT households. The group that should be closest to our middle-class household with three children is Goodin et al.'s (2008, p. 89) "German couples with children," which stands at a mean $D T$ of $11.2 \mathrm{~h}$ per adult per day. The three children in our FDT example being higher than the average number of children in the German group, the best comparison is with the FDT case in which the third child is compensated for by the au pair help. This FDT is $10.5 \mathrm{~h}$ per adult per day. In other words, the results do not seem dissimilar, which may strengthen confidence in both the FDT and DT methods.

Goodin et al. (2008, p. 92) contains data on lone parents, for example, in Germany with $D T=8.6 \mathrm{~h}$ per day. No comparison is possible with our lone parent example $(F D T=2.3 \mathrm{~h}$ per day), because the $D T$ outcome is an average over all incomes, not our minimum-wage extreme. Burchardt (2008, p.. 27, 69) shows, however, that figures around $F D T=0$ for lone parents appear quite possible in Western societies. One of her examples is a lone parent with two children and a moderately low wage rate, who is assessed as below both the time-poverty line and the money-poverty line in the paired indicator graph.

\section{(c) The preferred inefficient basic needs provision caveat}

People may display inefficiencies in time use, in the sense that an alternative behavior would give them more free time. Goodin et al. (2008, p. 11) mention an example of a corporate lawyer spending one hour per day on cleaning her house instead of hiring a helper at a lower wage rate than her own, and add that this brings no validity problem to $D T$. They are right if and insofar the inefficient behaviors take place within people's freely disposable time. In the FDT system, these choices become visible in people's FDT profile, without affecting the FDT level itself. Inefficient behaviors in the provision of basic needs do affect $F D T$, however. In the lawyer example, if this house cleaning is part of basic cleaning, her behavior gives her less FDT than she would have had by hiring a helper. Does that undermine FDT validity? Not if the behavior is not a free choice, for example, if she is afraid of helpers. Her actual, reduced $F D T$ then exactly represents the reduced freedoms she has due to her inflexibility. If her cleaning is a free choice, however, her freedoms are in fact higher than her FDT displays, because she now has some freedoms hidden in her non-FDT time for basic needs provision. Many other examples may be given, for example, a household preferring to supply all basic child care by itself in spite of available cheap daycare, or a farmer desiring to be independent and preferring a low-productive subsistence crop over an available cash crop for which he could have bought more food. In general, people's total "freedom time" is their FDT as assessed plus the time effect of freely chosen inefficiencies in basic needs provision, and the latter component will often differ from zero. This could be called the Preferred Inefficiencies in Basic Needs Provision caveat in FDT (and DT).

By definition, households may always remove these inefficiencies and create more FDT. Theoretically, the caveat may also be removed by the assessor on paper, for example, calculating how much FDT the corporate lawyer would have if she would hire a helper. Such a "corrected" or "potential" $F D T$ would theoretically be a superior measure, because of the certainty that actors cannot create more FDT than this. We would then need to know, however, what inefficiencies in basic needs provision reduce FDT to what extent, and whether these are really free preferences. Going after these questions will probably pay off only in specific cases, for example, studies on subsistence versus cash crops or the happiness that may come with less materialistic lifestyles. Our proposal, therefore, is to always stay alert on the fact that households will often have some possibilities to fine-tune choices in their basic needs provision and with that to 
enlarge their $F D T$, but accept plain $F D T$ as a good enough indicator in the majority of cases. This is analogous to accepting plain income or expenditure as good enough monetary indicators, even though we know that people are often not income maximizers (Ellis, 2000) or consumption optimizers (Linssen, Van Kempen, \& Kraaykamp, 2010).

\section{(d) The income value of FDT and the underemployment caveat}

The exploration of the value of FDT takes off from a reflection on the fungibility (substitutability) of time and money. Is this an empirical fact or an assumption? The calculation and the interpretation of $F D T$ differ in this respect. In the calculation, time/money fungibility is simply empirical. You do have to work so many hours to get so much money, and pay so much money to buy so many hours of others. With regard to the interpretation of the value of FDT once calculated, however, the picture is more complicated. As remarked already, the "full income" value of Becker (1965) assumes time/money substitutability also for hours that people do not in fact work. A person with an FDT of $8 \mathrm{~h}$ per day has a freedom to work $8 \mathrm{~h}$ per day above the hours needed for the household's necessities. People will usually work some of these hours, for example, in order to acquire extra consumables. For these actually worked hours, the same applies as for the calculation of FDT; their time/ money fungibility is simply factual. People will seldom spend all their FDT hours on work, however. The question then becomes: if people would decide to spend these hours on work too, would they earn the same wage rate as for the hours they currently work? The local context is decisive here. For female part-time workers in the United Kingdom, for instance, the wage rate of the extra hours will tend to be higher than of the current ones (Burchard, 2008, p. 65). In contexts of chronic underemployment, however, as in many of the lagging economies of Sub-Sahara Africa, the reverse may well be true. People may work a few hours per day for a reasonable return (e.g., on the farm) but then continue working for much lower rates, for example, as laborer. Hobbes et al. (2007) describe a case from Vietnam where people first fully exploit their most profitable land use option and then cascade down to other land use types with ever lower returns. This will create low income rates overall and with that, a low calculated FDT. In order to estimate the potential income that people could earn if they would decide to work all these FDT hours, the lowest wage rate of the local cascade should of course be taken for the extra hours.

Underemployment can be more severe than this, however. Income-generating options to fill the presently non-worked hours may simply be absent. People may then have more $F D T$ than in the case of available but poorly paid work, because the few hours of available work may as such have a reasonable income rate. Only, there is nothing to do with much of this FDT that generates income. ${ }^{3}$ This underemployment caveat differs much from the preceding one. Preferred inefficiencies in basic needs provision only result in a generally slightly too pessimistic FDT assessment. Severe underemployment results in a strongly over-optimistic interpretation of $F D T$ in a specific type of context. In situations of severe underemployment, either the FDT indicator should be joined with a monetary measure or the assessment should follow the paired time/money strategy (Section 2.3), so that severely underemployed households can be identified.

\section{(e) The freedoms and development value of FDT}

The productive household members can put their freely disposable time to any use allowed by local regulations, norms and markets, for example, to generate extra income for above-basic consumables, or savings, paying school fees or invest in landesque capital, but also to leisure, to build social capital, to join a training course, to migrate out, to give above-basic care to the children and so forth. In a general sense, therefore, FDT represents people's freedom to enjoy the present or to invest in the future ( $c f$. Alkire, 2006, p. 246). The subtitle of Goodin et al.'s (2008) book on Discretionary Time is: "A new measure of freedom" and indeed, FDT and DT appear to operationalize much of Sen's (1999) seminal freedoms concept. Relating FDT to some characteristic terms in livelihood studies, a household's FDT is the basis for its adaptive capacity, its capacity to invest and the negative of its vulnerability. Because households may decide to invest part of their FDT in what may be called development investments (in land quality, new skills, a business, and collective social capital), FDT may also be seen as a household's development capacity, and a key condition for any out-of-poverty strategy. 4

Local circumstances bring great variation in this freedoms and development value of $F D T$. This variation includes that of the income value (thus including the underemployment caveat) but more contextual factors are added, such as knowledge to know what to do, training and investment opportunities, credit facilities, freedom to organize, collective social capital, and enabling institutions. Hobbes (2010, p. 167) has designed an FDT-based indicator of village-level development potential that incorporates some of these factors and may be used for participatory self-analysis of communities.

\section{(f) The happiness value of FDT}

Would FDT correlate with subjective well-being and happiness? The expectation is that it should, since freely disposable time allows people to pursue the things they prefer to do or have, for example, do paid work for luxuries, leisure, or bake one's own bread. There are no data available that combine FDT with happiness (well-being and life satisfaction). Goodin et al. (2008, p. 58), however, report on a study that combined $D T$ with life satisfaction in Germany, in which DT has a stronger correlation than spare time with life satisfaction, and an equal strength as household income. ${ }^{5}$

At this point, it serves to briefly go back to the general "preferred inefficiencies of basic needs provision" caveat of FDT. If people prefer basic needs provision activities that are not fully $F D T$-maximizing, this has different consequences for the three values of $F D T$. If they would remove these preferred inefficiencies in order to maximize $F D T$, their potential income would increase. Their freedoms would remain the same, because they only shift freedoms from the basic needs provision to the nonbasic, FDT time compartment. Finally, assuming that their preferences are consistent with their well-being, their wellbeing would be reduced. In this case, more FDT does not mean more well-being.

\section{(g) The relative scientific merits of DT/FDT and monetary indicators}

GDP per capita is a well-known monetary indicator of wealth. GDP is often criticized from an ecological point of view. What does the GDP of a country mean if the country is at the same time accumulating waste, depleting its resources, and overfishing the ocean? Many proposals have been made to establish a corrected, "sustainable GDP" (e.g., De Groot, 1992, p. 242). At this point, we may note that exactly the same 
issue can be raised against $F D T$ or income. What does the $F D T$ or income of a farming household mean if it is at the same time accumulating toxic substances, mining its soil and over-exploiting the village forest? The basic rule appears to be that many validity issues pertaining to monetary indicators also pertain to integrated time/money indicators, and vice ver$s a$. People may not be $F D T$ maximizers but neither income maximizers, and like potential FDT, potential income may be the theoretically superior indicator. The income value of $F D T$ has its perfect mirror in the time value of freely disposable income. How much time can money buy? Can local contexts also display over-employment, with many people unable to work less for less income (Goodin et al., 2008)?

Any discussion on the scientific pros and cons of integrated time/money versus purely monetary indicators should focus on where these indicators really differ rather than on what they have in common, and be strongly tied to the research aim. Based on the present discussion, the following general observations may be relevant.

(1) Simply because they are new, time/money integrated indicators can open up new avenues of looking at societies, households, and development, for example, connected with welfare regimes, environmental degradation, class formation, well-being, poverty traps, unpaid work, gender, HIV/AIDS and many other issues.

(2) Probably, all indicators have their own specific interpretation caveats apart from the ones they have in common. As discussed for FDT, for instance, this is its interpretation toward potential income in contexts of severe underemployment. Yet the possibility to at least approach potential income is a relative strength of FDT (and $D T$ and the paired indicators), because monetary indicators lack this possibility.

(3) Around $F D T=0$, there are no $F D T$ interpretation uncertainties because people have no $F D T$. In that range, therefore, interpretation uncertainties cannot outweigh the intrinsic power of the integrated FDT (or $D T$ ) metric compared to one-dimensional time or money indicators. $F D T=0$ may well be a uniquely valid universal poverty line.

(4) More $F D T$ will quite often mean more potential income and well-being, but certainly not always, as discussed. The freedoms and development potential value of $F D T$ appears to be the most straightforward of the three $F D T$ values discussed, in the sense that within each local context and for each household, more FDT always means more freedoms and more development capacity.

\section{CONCLUSION}

This paper has developed a methodology of time/money integrated livelihood assessment that is conceptually coherent and empirically robust. "Freely disposable time" (FDT) is defined as the time that a household's productive adults have left after fulfilling the basic needs that they need to supply for themselves and their dependents. Basic needs comprise physiological needs, food, shelter and care needs, social obligations, basic consumer goods, and so on. FDT is the freedom that people have to engage, within the range of their agency and options available in the local context, in activities that generate above-basic consumables, in physical or social investments for the future, in the above-basic caregiving or leisure.

In the FDT methodology, the actual income rate of the household is used to convert money into time needs for each category that the household spends time and/or money on.
Households can have deficits or surpluses on each category, expressed in hours per day. The total of surpluses minus deficits is FDT. An FDT of zero implies that people need all their time to satisfy their household's basic time and money needs and are trapped in work for bare survival; $F D T=0$ is the absolute poverty line. An $F D T$ above zero (e.g., $F D T=2 \mathrm{~h} /$ day) may be necessary for households to invest in out-of-poverty strategies.

Independent from FDT, Goodin et al. (2008) have developed the "Discretionary Time" (DT) concept and methodology. DT and FDT are conceptually equivalent but differ in many elements of method. For instance, $D T$ takes basic needs as largely relative, does not distinguish between separate time surpluses and deficits and is more geared to work with national statistics in developed countries.

In order to test its robustness, the FDT framework has been applied to complex livelihoods of peri-urban farming households in India, with some cases from the Netherlands added for comparison. In India, $F D T$ was assessed as $10.8 \mathrm{~h}$ per day for the richest household and as 5.4 and $5.5 \mathrm{~h}$ per day for two poor households. In the Netherlands, a middle-class household with three small children was found to have $F D T=8.8 \mathrm{~h}$ per day, while a minimum-wage lone mother with three small children stood at $F D T=2.3 \mathrm{~h}$ per day. The one $F D T$ case that could be compared with $D T$ data showed similarity of $D T$ and $F D T$ outcomes.

Being a single quantitative measure, $F D T$ is suitable for comparative and monitoring purposes, comprising the whole range of rich and poor, rural and urban. Its methodology also allows for scenario studies (Table 1), for example, on the effects of different livelihood strategies, the effects of macro-level shifts in prices, wages, tax or welfare regimes, and the effects of micro-level changes, for example, children being born, HIV/ AIDS spreading, soils degrading, wells drilled close to homes, or solar cookers supplanting firewood gathering. Other FDT applications may work the other causal way around, for example, studying the effect of changes of FDT (e.g., through development aid) on investments in education, social capital, business initiatives, or land quality.

People may have preferences that lead to inefficiencies in the provision of their basic needs. It should, therefore, be borne in mind that people may have a higher potential income, more freedoms and higher well-being than suggested by their FDT. Apart form this general caveat (which is acceptable in most cases in our view), the interpretation of what the value of FDT is to households always requires caution. First of all, the local context (markets, regulations, and social norms) determines what people can actually do with their freely disposable time. Contexts of severe underemployment represent a real caveat here, especially for the potential income interpretation of FDT. Adding an income indicator is advisable here.

Several issues of metric validity are shared or mirrored between FDT and monetary indicators. For instance, both FDT and income may be environmentally unsustainable, and households may not be fully maximizing their FDT or income. A number of relative strengths of $F D T$ (and $D T$ ) appear to stand out. They are its capacity to shed a new light on persistent problems, its capacity to capture time burdens of households, its openness to assess potential incomes in contexts without severe underemployment, its possible connection with well-being and its straightforward interpretation as a metric of freedoms. Finally, $F D T=0$ may be a very robust universal poverty line.

Any decision on what will be the focal indicators of research and statistics-FDT, $D T$, monetary indicators, paired indicators or any mix-will involve trade-offs. Data needs of 
integrated or paired metrics, requiring as they do information on time use as well as cash flows, will be higher than of monodimensional indicators such as income. Moreover, needs of comparability should be considered. If these are relatively low, it may serve to maintain more intra-group detail and keep time and money outcomes separate in a paired rather than an integrated indicator. Finally, as discussed above and in the preceding section, a whole group of scientific considerations pertain to research aims and metric validity. Major reasons to adopt $F D T$ or some likewise integrated time/money metric are its strong validity to gauge what may be called real poverty, its (cautious) connections with potential incomes and actual well-being and, in contexts without severe underemployment, its straightforward interpretation as people's freedom of choice. This freedom is a prime value in itself and also a key element in the development capacity of any person, household or community.

\section{NOTES}

1. In passing, Goodin et al. (2008,p. 19) make the same choice, saying that "it matters how far above the poverty threshold people are (in our terms, how much 'discretionary time' they enjoy)." Reardon and Vosti (1995) have proposed the term "investment poor" for households that avail of only a little more than bare basic needs satisfaction, assuming that they will spend this little surplus on expanded consumption rather than investment (in knowledge, soil and water conservation, social capital, etc.) In FDT terms, an FDT of, say, 2 h/day may be set as the "investment poverty line."

2. Productive adults were defined as all non-handicapped or chronically ill individuals between 13 and 60 years of age. The 13 years limit was chosen because schooling up to 12 years of age was set as a basic need. Above that age, the choice to work or go to school is free, that is, part of FDT.

3. We thank an anonymous reviewer for this observation.

4. Looking at land degradation issues more specifically, Reardon and Vosti (1995) assert that the criterion for poverty in environment-poverty analysis should be people's "ability to make minimum investments in resource improvements to maintain or enhance the quantity and quality of the resource base." In the same vein, Burger and Zaal (2009) regard farmers' investments in the quality of the land as the key determinant in the bifurcation between the pathways of Malthusian degradation and neoBoserupian restoration under circumstances of growing land scarcity. Note that for households to really invest in the future, environmental or otherwise, they do not only need the investment capacity expressed in
FDT plus the necessary knowledge, but also a motivation to invest, which will depend largely on expected yields and risks of the investments. In land use decisions, this translates to a high degree to the presence of good soils and markets (Burger \& Zaal, 2009; Hyden, Kates, \& Turner, 1993) but also to risk-reducing institutions (e.g., Rahman, De Groot, \& Snelder, 2008).

5. The overall explanation of variance remains relatively low, however, probably because well-being will always depend on more than time and money. The first two profiles in Table 1, for instance, have the same FDT but differ in income, sleep and self-care, savings and food. What creates more well-being depends on the actor's preferences for these factors.

6. To deal with children being sent to daycare, we divided the care need of children into "family care" and "daycare." The former includes time needed for helping children to dress, bring them to school, read a bedtime story, etc. that can only be provided by people in the house. Daycare then refers to the need for children to be looked after for the rest of the day at daycare or school or as a secondary activity during the household chores or leisure time. The time expenditures and needs on the latter category have been left out in our framework, financial cost of daycare is included as basic need.

7. Households that live on non-labor income only could be said to need zero hours for its acquisition, creating an infinite $I N C$ and error flags all over the database queries. This is only a technical problem, however, solved by allocating any minor time slot to the acquisition.

\section{REFERENCES}

Alkire, S. (2002). Valuing freedoms. Oxford: Oxford University Press. Alkire, S. (2006). Needs and capabilities. In S. Reader (Ed.), The philosophy of need (pp. 229-251). Cambridge: Cambridge University Press.

Bardasi, E., \& Wodon, Q. (2006). Measuring time poverty and analyzing its determinants: Concepts and application to Guinea. Economics Bulletin, 10(10), 1-7.

Bardasi, E., \& Wodon, Q. (2009). Working long hours and having no choice; time poverty in Guinea. Policy Research Working Paper 4961. Washington, DC: The World Bank.

Becker, G. S. (1965). A theory on the allocation of time. Economic Journal, 75, 493-517.

BLS, Bureau of Labor Statistics. (1997). BLS handbook of methods. $<$ http://www.bls.gov/opub/hom/homtoc_pdf.htm>.

Burchardt, T. (2008). Time and income poverty. CASE report 57. London School of Economics, London

Burger, K., \& Zaal, F. (Eds.) (2009). Sustainable land management in the tropics: Explaining the miracle. Farnham: Ashgate Publishers.

Campbell, A., Converse, P. E., \& Rogers, W. L. (1976). The quality of American life. New York: Russell Sage.

Carter, M. R., \& Barret, C. B. (2006). The economics of poverty traps and persistent poverty: An asset-based approach. Journal of Development Studies, 42(2), 178-199.
Chambers, R., \& Conway, R. (1992). Sustainable rural livelihoods: Practical concepts for the 21st century. IDS Discussion Paper, No. 296. Institute of Development Studies, Brighton.

Chandrasekhar, C. P., \& Ghosh, J. (2003). The calorie consumption puzzle. The Hindu Business Line, Feb.11.

De Groot, W. T. (1992). Environmental science theory; Concepts and methods in a one-world, problem-oriented paradigm. Amsterdam: Elsevier Science Publishers. $<$ http://openaccess.leidenuniv.nl/dspace/ bitstream/1887/11548/1/11_511_207.pdf>.

Douthitt, R. A. (2000). Time to do the chores?" Factoring homeproduction needs into measures of poverty. Journal of Family and Economic Issues, 21(1), 7-22.

Ellis, F. (2000). Rural livelihoods and diversity in developing countries. Oxford: Oxford University Press.

Folbre, N. (2004). A theory of the misallocation of time. In N. Folbre, \& M. Bittman (Eds.), Family time: The social organization of care (pp. 7-24). London: Routledge.

Gershuny, J. (2005). Busyness as a badge of honour for the new superordinate working class. Institute for Social and Economic Research working paper 2005-9. University of Essex, Colchester.

Giampietro, M. (2004). Multi-scale integrated analysis of agroecosystems. Florida: CRC Press. 
Gomiero, T., \& Giampietro, M. (2001). Multiple-scale integrated analysis of farming systems: The Thuong Lo Commune (Vietnamese uplands) case study. Population and Environment, 22(3), 315-352.

Goodin, R. E., Rice, J. M., Parpo, A., \& Eriksson, L. (2008). Discretionary Time: A new measure of freedom. Cambridge: Cambridge University Press.

Grünbühel, C. M., \& Schandl, H. (2005). Using land-time-budgets to analyse farming systems and poverty alleviation policies in the Lao PDR. International Journal of Global Environmental Issues, 5(3/4), $142-180$

Hobbes, M. (2005). Material flow accounting of rural communities: Principles and outcomes in South East Asia. International Journal of Global Environmental Issues, 5(3/4), 194-224.

Hobbes, M., Stalpers, S. I. P., Kooijman, J., Le, Thi, Than, Thu, Khanh, Trinh, et al. (2007). Material flows in a social context: A Vietnamese case study combining the material flow analysis and action-in-contextframeworks. Journal of Industrial Ecology, 11(1), 141-159.

Hobbes, M. (2010). Figuring rural development: Concepts and cases of land use, sustainability and integrative indicators. Leiden University Press, Leiden. < http://openaccess.leidenuniv.nl/dspace/handle/1887/ $15036>$.

Hussein, K. (2002). Livelihoods approaches compared: A multi-agency review of current practice. Department for International Development, Overseas Development Institute. Finesse Print, UK.

Hyden, G., Kates, R. W., \& Turner, B. L. (1993). Beyond intensification. In B. L. Turner, G. Hyden, \& R. W. Kates (Eds.), Population growth and agricultural change in Africa (pp. 410-439). Gainesville: University of Florida Press.

Lanjouw, J. O., \& Lanjouw, P. (2001). How to compare apples and oranges: Poverty measurement based on different definitions of consumption. Review of Income and Wealth, 47(1), 25-42.

Linssen, R., Van Kempen, L., \& Kraaykamp, G. (2010). Subjective wellbeing in rural India: the curse of conspicuous consumption. Social Indicator Research, doi:10.1007/s11205-010-9635-2.

Pastore, G., Giampietro, M., \& Ji, Li. (1999). Conventional and land-time budget analysis of rural villages in Hubei province, China. Critical Reviews in Plant Sciences, 18(3), 331-357.

Rahman, S. A., De Groot, W. T., \& Snelder, D. J. (2008). Exploring the agroforestry adoption gap: Financial and socioeconomics of litchibased agroforestry by smallholders in Rajshahi (Bangladesh). In D. J. Snelder, \& R. D. Lasco (Eds.), Smallholder tree growing for rural development and environmental services (pp. 227-243). Dordrecht: Springer.

Ravallion, M. (1994). Measuring social welfare with and without poverty lines. The American Economic Review, 84(2), 359-364.

Ravallion, M., \& Bidani, B. (1994). How robust is a poverty profile?. The World Bank Economic Review, 8(1), 75-102.

Reader, S. (2006). Does a basic needs approach need capabilities?. The Journal of Political Philosophy, 14(3), 337-350.

Reardon, T., Crawford, E., \& Kelly, V. (1994). Links between non-farm income and farm investment in African households: Adding the capital market perspective. American Journal of Agricultural Economics, 76(5), 1172-1176.

Reardon, T., \& Vosti, S. A. (1995). Links between rural poverty and the environment in developing countries: Asset categories and investment poverty. World Development, 23(1), 1495-1506.

Rojas, M. (2008). Experienced poverty and income poverty in Mexico: A subjective well-being approach. World Development, 36(6), 1078-1093.

Romero, M. R. (2006). Investing in the land: Agricultural transition towards sustainable land use in the Philippines forest fringe. Leiden University, Leiden. <http://openaccess.leidenuniv.nl/dspace/handle/ $1887 / 4352>$.

Sen, A. K. (1981). Poverty and famines: An essay on entitlements and deprivation. Oxford: Clarendon.

Sen, A. K. (1987). The standard of living. Cambridge: Cambridge University Press

Sen, A. K. (1999). Development as freedom. New York: Knopf Press.

Scoones, I. (1998). Sustainable rural livelihoods: A framework for analysis. IDS Working Paper, No. 72. Institute of Development Studies, Brighton.

Shelley, K. J. (2005). Developing the American time use survey activity classification system. Monthly Labour Review, 128(6), 3-15.

Stewart, F. (1985). Basic needs in developing countries. Baltimore, MD: Hopkins University Press.
Streeten, P. P. (1979). Basic needs: Premises and promises. Journal of Policy Modeling, 1, 136-146.

Streeten, P. P., Burki, S. J., ul Haq, M., Hicks, N., \& Stewart F. (1981) First things first: Meeting basic needs in developing countries. New York: Oxford University Press.

Van Campenhout, B. F. H. (2006). Locally adapted poverty indicators derived from participatory wealth rankings: A case of four villages in rural Tanzania. Journal of African Economies, 16(3), 406-438.

Vickery, C. (1977). The time-poor, a new look at poverty. The Journal of Human Resources, 12(1), 27-48.

Wodon, Q. (1997). Food energy intake and cost of basic needs: Measuring poverty in Bangladesh. Journal of Development Studies, 34(2), 66-101.

\section{APPENDIX A}

\section{A.1 Livelihood activities and basic needs}

The time span of $F D T$ assessment should preferably cover a full year, so as to include seasonal variation. Table 3 provides the classification of livelihood activities used for the field study in Kashimpur. The list blends the most important categories in time allocation studies (Shelley, 2005) and the main components of consumer-expenditure surveys (BLS, 1997). Most of the categories have a basic need component, expressing a relatively broad definition of the term that includes, for instance, the care need of children and a minimum of leisure time, for example, to maintain social contacts. For the Kashimpur case study, the caloric food needs have been quantified following FAO standards, while the other basic needs have been based on the local situation, for example, the minimum time it takes to keep up a basic house, cook a basic meal, or the minimum cost of access to a mobile phone for emergencies. In the basic needs figures for the Dutch case study, most needs expressed in time are kept equal to the Indian case. For the Dutch monetary basics we used our own guesstimates, combined with data on minimum wage, governmental subsidies, and minimum welfare standards. Access to internet has become basic, for instance, to participate in Western societies. 6

\section{A.2 Formal methodology of the FDT assessment}

Figure 1 shows the $F D T$ assessment framework. It starts out with the classification of categories $(A, B, C, \ldots$, i) on which households may spend time and/or cash. The first (upper left-hand corner) element of the figure is the calculation of the basic needs that have to be provided for by the productive adults (PAs), based on the household composition.

The three blocks in the upper left-hand corner together assess the degree to which, within each category, the productive adults have "acquired" more or less than the household's basic needs, that is, a surplus or deficit in that category. "Acquired" is defined as self-produced plus received as remittance, rent, help or aid (in cash, time or equivalents). "Self-produced" may denote cash from wage labor or food from the farm but also self-"produced" hours of sleep, leisure, self-care, or care given to dependents. "Help" may refer to, for instance, the grandmother assisting with the children. "Aid" may be food aid from the government or free seedlings supplied by an NGO. The deficit/surplus calculations will often require conversions between the field-level data and the units in which the basic need is defined, for example, from bags of rice to calories. As the figure shows, surpluses and deficits are kept sep- 
Table 3. Categories of human activities and basic needs (referred to as $A, B, C, \ldots, i$ in Figure 1) to be provided by the producing adults ( $P A$ ) of the households in the Kashimpur case study, India complemented with values used in the Dutch case study. Basic needs mainly follow guesstimates based on minimum requirements in the local situation estimated by key respondents and secondary sources, such as the social welfare minimum in the Netherlands. Cash is expressed in US\$ per day (1 US\$ $=40$ INR $=0.7$ euro). Care basic needs exclude care that can be given simultaneously with cooking, chores, etc

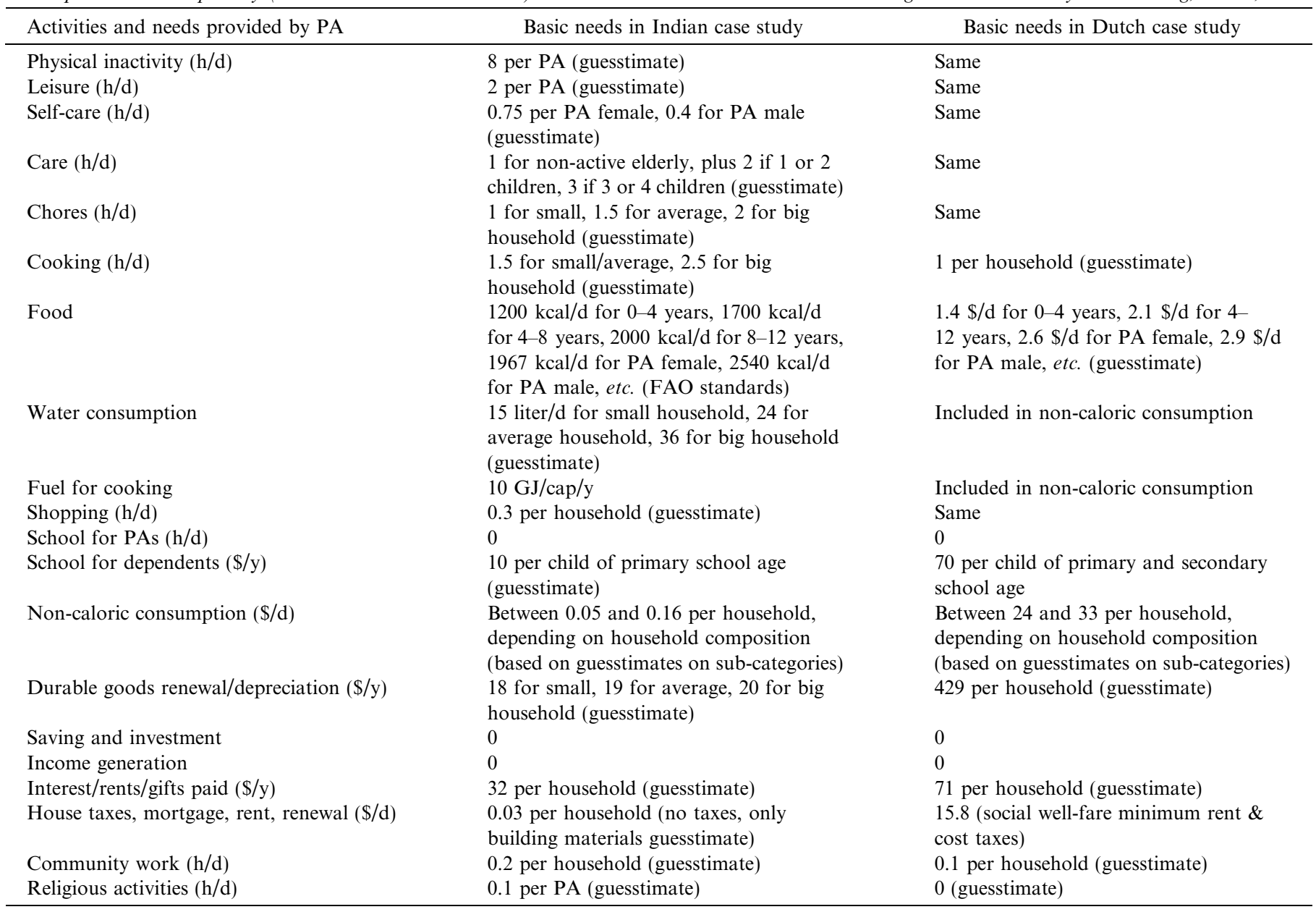

arate. Each category has either a surplus with the deficit set at zero, or the reverse. This allows keeping track of how households may suffer chronic deficits or may create more time for work and other categories may by accepting temporary deficits. Categories with a basic need at zero automatically show surpluses, except for the savings/investments category where a deficit will show up for households with a negative cash balance.

The next three (lower left-hand corner) blocks of the framework assess the time equivalence of the time and cash that the productive adults spend on the acquisition of each category. Expenditures may be incurred in time $(E X h)$, in money $(E X \$)$ or both, for example, if care is self-produced $(E X h)$ and supplemented by hiring a nanny $(E X \$)$. Cash income is defined as negative cash expenditure, so that over all categories including income generation and savings, the $E X \$$ 's add up to zero. As Figure 1 shows, all cash expenditures are converted to the equivalent hours of working time by using the cash income per hour of the household (INC) as conversion factor, with INC including all cash influx components (wages, marketed farm produce, pensions, etc.), divided by the numbers of hours involved in getting that income. This is then added to the direct time spent on the category $(E X h)$ to obtain the time/cash integrated time equivalents expended (Tex) on the category. In formula, Tex $=E X h+E X \$ / I N C$. Over all categories, Tex adds up to $24 \mathrm{~h}$ /day per PA, because $E X h$ expresses all that the PA actually does during the day and the sum of all $E X \$$ 's is zero.

The income per hour may be very high, and hence the $E X \$ /$ $I N C$ factor very low, for households that live primarily on rents, welfare, remittances or other non-labor income, since they spend hardly any time on its acquisition. ${ }^{7}$ Note, however, that INC cannot be used to calculate what a household might earn if it would convert some of its FDT into cash; the income rate that should then be taken should reflect the household's position on the local labor market - see the underemployment discussion in the main text.

This system with acquisition and expenditure running parallel for each category can handle all real-life complexities and is conceptually robust, for example, if basic needs are added or set to zero. The system can handle very complex activities such as mixed subsistence/commercial agriculture. Of its subsistence part, the harvest is entered into the acquisition account (e.g., in the food category as kcal) and its time and cash inputs are entered as $E X h$ and $E X \$$ in the expenditures and its cash inputs are entered as $E X \$$ in the same category. The commercial part of the agriculture is an element in the income-generation activities, with the net profits entered in the acquisition account and (with negative sign) in the expenditure account $(E X \$)$. The time spent on it is again an $E X h$ in the expenditures account. If 


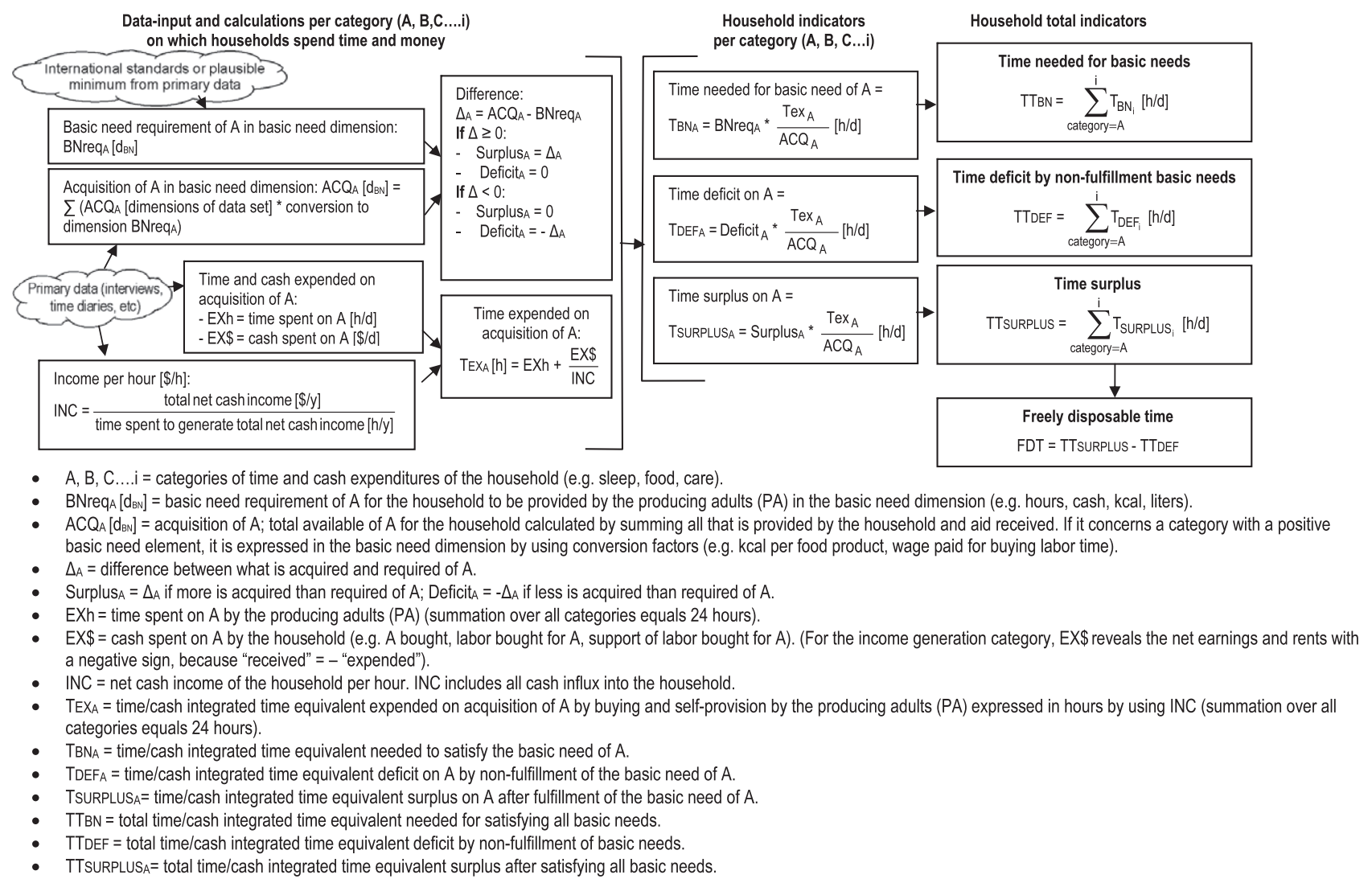

Figure 1. Freely disposable time: the empirical system (livelihood assessment). All elements are expressed per producing adult (PA) member of the household per day.

farmers are investing, for example, in land acquisition or terracing, this could be kept visible by entry in the savings/investments category.

With these inputs, the next column of Figure 1 calculates the time/cash integrated time indicators per category. The structure of the formulas is simple. If, for instance, the basic food need of a household is $2000 \mathrm{kcal} /$ day per PA and if the actual acquisition is $3000 \mathrm{kcal} /$ day per PA, and if the PAs spend a time/cash equivalent (Tex) of $3 \mathrm{~h}$ per day on this, the time needed to acquire the basic food need ( $\left.T_{B N \text { food }}\right)$ is two-thirds of this time or, formally in the system, $(2000 \mathrm{kcal} /$ day $) *(3 \mathrm{~h} /$ day $) /(3000 \mathrm{kcal} /$ day) $=2 \mathrm{~h} /$ day for each PA. Along this line, we get:

(1) $T_{B N}$, being the time/cash integrated time equivalent required per PA to satisfy the household's basic need in the category.

(2) $T_{D E F}$ and $T_{\text {SURPLUS }}$, being the time/cash integrated time equivalent per PA expressing the degree to which the household lives with a deficit or surplus, respectively, relative to the basic need in the category.

(3) FDT, defined as the aggregate of all surpluses minus all deficits.

\section{A.3 An option for minimizing data intensity}

The FDT assessment methodology offers full insight in the key elements of livelihoods. Data requirements are high, however, and we, therefore, present one lean option that could be used in broad $F D T$ surveys without sacrificing too much empirical insight. This version drops detail for instance in the contributions of non-productive household members and in possible deficits per basic need category. The protocol runs as follows. As in the full FDT system, the household composition needs to be known in some detail, to generate all the basic needs elements of the household. The next step is to translate these basic needs into time and cash requirements for the productive adults, mainly using local data. Examples are (a) the drinking water need will be translated into either water fetching time or water buying cash or a mixture of these, (b) most consumables can be translated directly into cash needs, (c) the food requirement (in kcal/day) can be split into auto-produced food (kcal) and bought food (cash); the auto-produced food in its turn can be translated into hours of work and cash for the necessary inputs. All time and monetary units can now be added up to produce a cost of basic needs per PA $(C B N)$, composed of the requirement in hours $(t C B N)$ plus the requirement in $\operatorname{cash}(c C B N)$. The total income rate (INC) of the household needs to be known, as in the preceding subsection. The time needed to satisfy the basic needs is: $T_{B N}=t C B N+c C B N / I N C$. Freely disposable time is: $F D T=24-T_{B N}$. In overall research designs, shortcut $F D T$ scans can be combined with full $F D T$ assessments in order to balance empirical quality and budget limits (Lanjouw \& Lanjouw, 2001). 